\title{
Economic implications in inflammatory bowel disease: results from a retrospective analysis in an Italian Centre
}

Angela Variola ${ }^{1}$, Arianna Massella ${ }^{2}$, Andrea Geccherle ${ }^{1}$, Paolo Bocus ${ }^{2}$, Roberto Tessari ${ }^{3}$, Teresa Zuppini ${ }^{3}$, Roberto Ravasio ${ }^{4}$

${ }^{1}$ IBD Unit, Ospedale Sacro Cuore - Don Calabria di Negrar Verona, Italy

2 Unit of Gastroenterology, Ospedale Sacro Cuore - Don Calabria di Negrar Verona, Italy

${ }^{3}$ Hospital Pharmacy, Ospedale Sacro Cuore - Don Calabria di Negrar Verona, Italy

${ }^{4}$ Health Publishing \& Services, Milan, Italy

\begin{abstract}
BACKGROUND: Inflammatory bowel disease (IBD) represents a group of chronic conditions characterized by elevated costs. Over the last years, also a considerable healthcare burden associated with IBD has emerged, due to an increasing use of biological drugs and hospitalization costs. Despite the creation of local or regional databases, data regarding healthcare expenditure are lacking in Italy.

AIM: To evaluate the treatment cost (biological drugs and hospitalizations) for patients with ulcerative colitis (UC) or Crohn's disease $(\mathrm{CD})$ treated with biological drugs.

METHODS: Disease severity was evaluated by clinical scores (partial Mayo score and Harvey Bradshaw Index). We analyzed retrospectively patients treated with biologics referred to our IBD Unit between May 2015-April 2016 who underwent at least six months of follow-up (last visit October 2016). We calculated a mean cost per month of treatment for each patient. We also investigated the presence of any correlation between the monthly cost of treatment and demographic or clinical variables.

RESULTS: We enrolled 142 patients ( $52 \mathrm{UC}$, mean age 44.3 years, male 40.4\%; $90 \mathrm{CD}$, mean age 38.8 years, male 56.7\%). About half of CD patients (48.9\%) underwent previous intestinal surgery. The disease severity was higher in UC group vs CD group. In UC group infliximab was the most prescribed biologic (51.9\%), followed by golimumab (26.9\%) and adalimumab (21.2\%). While CD patients were treated with adalimumab in $54.4 \%$ and infliximab in $45.6 \%$. The mean monthly cost of treatment was $€ 1,235.41 \pm 358.38$ for $\mathrm{UC}$ and $€ 1,148.92 \pm 337.36$ for $\mathrm{CD}(\mathrm{p}=0.16)$. In both groups expenditure due to biologics amounts for more than $80 \%$. We found a correlation between costs and disease activity (UC: $\mathrm{p}<0.01$; CD: $\mathrm{p}<0.01)$.

CONCLUSION: The main cost is due to biological drugs, but patients enrolled were the most severe in comparison to the whole IBD population under conventional therapy. As no cost differences were found between biologic drugs and the way of administration (intravenous or subcutaneous), the therapeutic choice should be driven by clinical reasons and not only economic ones.
\end{abstract}

\section{Keywords}

Inflammatory Bowel Disease; Ulcerative Colitis; Crohn's Disease; Biological drugs

\section{INTRODUCTION}

Inflammatory Bowel Disease (IBD) is a group of conditions characterized by an immune-mediated, systemic and chronic inflammation of the gastrointestinal tract, and includes Ulcerative Colitis (UC) and Crohn's Disease (CD) [1]. In Italy, the number of patients suffering from IBD can be estimated at between 150,000-200,000 cases, with an annual incidence of approximately 10,000 cases [2]. These diseases mainly affect the age range 15-40 years [3]. In particular, UC shows the highest incidence between 20 and 40 years, while Crohn's disease in the age range 15-35 years [3]. Men and women are equally affected [4]. Like most chronic diseases, IBD results in a significant reduction in the quality of life [5], while representing a high consumption of healthcare resources (drugs, hospitalizations, etc.) [6,7].
Corresponding author Roberto Ravasio rravasio@aboutpharma.com 
The clinical spectrum of IBD is very broad, and ranges from asymptomatic to serious disease states. Although the etiology of IBD has not yet been well defined, aspects such as genetics, intestinal microbiome and the immunomodulatory responses influenced by the environment are the target of the new therapies [8]. The therapies currently approved for the treatment of $\mathrm{UC}$ or $\mathrm{CD}$, whose goal is to reduce the inflammatory status, include aminosalicylates, corticosteroids, immunomodulators and biological drugs $[9,10]$. The latter may be divided into two main categories: anti-tumor necrosis factor (anti-TNF) drugs (eg. infliximab, adalimumab, golimumab) and anti-integrin drugs (vedolizumab) [1,11]. With the increased use of biologics, more expensive than standard therapies, the expenditure generated by IBD increased: UC and CD also generate a significant economic impact, both for the individual patient and for the Healthcare System [11-15].

The necessity for a more targeted control of healthcare spending generated the need to have detailed information on the consumptions and costs related to the single diseases. However, despite the presence in Italy of numerous local or regional administrative databases, such information is often not available, or partly incomplete (due to the administrative nature of the databases, the demographic and clinical information needed for the characterization of patients are limited). As a result of this scenario, the current level of knowledge about healthcare costs and the profiles of patients with IBD is very low.

The purpose of this analysis is to define the treatment cost (biologics and hospitalizations) associated with a group of patients with UC or CD referred to a Center located in Northeastern Italy, and examine this cost compared to some demographic and clinical variables.

\section{METHODS}

\section{Setting and analysis perspective}

The investigative scope of this analysis is represented by the population referred to the Multi-specialist Center for Rectal-Intestinal Diseases of the Ospedale Sacro Cuore - Don Calabria di Negrar (hereinafter simply referred to as the "Center"), located in Northeastern Italy.

The cost analysis was carried out by adopting the perspective of the Italian National Health Service (NHS), thus considering only direct medical costs (biological drugs and hospitalizations).

\section{Data source and definition of sample}

The retrospective, observational and non-interventional analysis considered all subjects who, diagnosed with UC or CD and treated with biological drugs, were referred to the Center during the period May 2015-April 2016. The cases were identified retrospectively, thanks to the access to the archives of the Center. Each patient enrolled was subjected to a follow-up of at least six months. The follow-up was concluded in October 2016.

The archives of the Center allowed to recover for each patient a series of demographic and clinical information, plus other information on the consumption of resources, as detailed below. The diagnosis of UC or CD was clinically confirmed on the basis of what indicated in the medical records. Patients with other diagnoses (eg. diverticulitis) were excluded.

\section{Demographic and clinical data}

The detailed demographic and clinical data was extrapolated from the records contained in the archives of the Center. These include age, gender, weight, type of IBD (UC or CD) and age of onset, duration, severity and site of the disease. For UC the disease site was coded as pancolitis, left colitis, proctitis or ileal colitis, while for $\mathrm{CD}$ the ileocolic, ileal, colic or proctitis sites were coded.

Two different scales were considered to evaluate the severity of IBD: the Mayo Score for UC [16,17] and the Harvey-Bradshaw Index (HBI) for CD [19]. Considering four components (defecation frequency, rectal bleeding, endoscopic evaluation and overall assessment), the Mayo Score defines the severity of the disease using four discrete states: i) remission, ii) mild activity, iii) moderate activity, and iv) serious activity $[16,17]$. On the basis of five exclusively clinical parameters (patient well-being, abdominal pain, number of liquid or soft evacuations, abdominal mass, presence of complications), the HBI also defines the severity of the disease, using the same four discrete states of the Mayo Score (remission, mild activity, moderate activity and severe activity) [19,20].

\section{Consumption and costs of resources}

Information about health resources consumed by patients along the observation period were also extrapolated from the records of the archives of the Center. Only the resources used for the treatment of UC or CD were included. In particular, biological drugs and hospitalizations finalized to the management of the two diseases were considered. For each bio- 
logical drug the date of beginning and end of administration, the presence of induction (if the first administration of the biological drug occurred concomitantly with or after the date of enrollment), the dose administered, the number of infusions and the possible reason for suspension were indicated. The admitting department, the hospitalization length and the related diagnosis-related group (DRG) were instead indicated for each hospitalization.

Upon their enrollment, patients were administered one of the following biological drugs: i) adalimumab subcutaneously (SC), with the double indication for UC and CD, ii) golimumab SC with the sole indication for UC and iii) infliximab intravenous (IV) with the double indication for UC and CD. The cost of the biological drugs was calculated by detecting for each individual patient the actual cost incurred by the hospital pharmacy of the Center. For each biological drug, it was then considered the relative purchase price, net of all discounts (mandatory and not). These prices, being referred to a period of 18 months, in fact reflect the relative average price paid by the hospital pharmacy. For adalimumab it was therefore considered an average price of $€ 491.50$ for a $40 \mathrm{mg}$ pre-filled pen, while for golimumab an average price of $€ 1,038.33$ was used both for the $100 \mathrm{mg}$ and the $50 \mathrm{mg}$ pre-filled pens. The average price per milligram of infliximab amounted to $€ 4$ 4.05. Finally, hospitalizations were quantified thanks to the relevant DRG rates [21].

\section{Analysis of the costs of treatment}

On the basis of the data collected, as a first objective of this analysis an average treatment cost in relation to the two IBDs was estimated. Since, on the basis of the enrollment criteria, the follow-up for each patient may vary from a minimum of six months to a maximum of 18 months, it was decided to present the data in the form of mean cost per month of treatment, thus avoiding any extrapolation bias (eg. at Month 12, 18 or 24). This cost was calculated by dividing the total treatment cost associated with each patient (biological drugs and hospitalizations) by the relevant number of months of follow-up.

The mean cost per month of treatment was then investigated, in light of other variables such as gender, age, comorbidities, treatment lines, route of administration and active ingredient. The last three types of analysis proposed deserve a more in-depth examination. In the first of these, we tried to verify whether the switch to a second and/or third line of treatment could result in an increase in the treatment cost. Three classes were there- fore identified: i) first-line treatment (use of a single biological drug during the observation period), ii) second-line treatment (use of two biological drugs during the observation period) and iii) third-line treatment (use of three biological drugs during the observation period). Since in some cases the patient may discontinue the biological treatment without then beginning a subsequent one (eg. surgery, auto-suspension, etc.) other two classes were added: iv) second-line treatment without any subsequent biological drug and v) third-line treatment without any subsequent biological drug. The second analysis proposed is instead aimed at identifying any differences between the costs per month of treatment, depending on the type of administration of the biological drug (subcutaneous or intravenous). Finally, in the third analysis we tried, where possible, to define homogeneous subgroups (same route of administration, same severity, exclusion of patients with surgery or prior administration of biological drugs) in order to investigate the presence of differences in the mean cost per month of treatment depending on the active ingredient administered.

\section{Data analysis}

Quantitative variables have been described as mean value ( \pm standard deviation), categorical variables as numeric value (percentage). The significance of the differences between the data found/processed was verified by applying the Student's two-tailed t-test. The correlations between the data found/processed was verified by applying the Pearson's two-tailed r-test. The analysis was supported by Microsoft ${ }^{\circledR}$ Excel $^{\circledR}$ for Windows ${ }^{\circledR}$ (Microsoft Corporation, Seattle, WA, USA) and SPSS $^{\circledR} 13.0$ for Windows ${ }^{\circledR}$ (SPSS Inc., Chicago, IL, USA).

\section{RESULTS}

\section{Characteristics of the sample}

During the enrollment period, 144 patients diagnosed with IBD were referred to the Center. Of these, two patients (both diagnosed with CD) did not meet the inclusion criteria, since the relevant follow-up period was less than six months. Overall, in the analysis 142 patients were then considered, including 52 with a diagnosis of UC (mean age: 44.3 \pm 13.7 years; males: $40.4 \%$; weight: $70.8 \pm$ $14.1 \mathrm{~kg}$ ), and 90 diagnosed with CD (mean age: $38.8 \pm 13.9$ years; males: $56.7 \%$; weight: $69.4 \pm 15.5 \mathrm{~kg}$ ). In both cases the number of people suffering from UC or CD reached the maximum concentration in the age range 1945 years (UC: $57.7 \%$; CD: $63.3 \%$ ), to gradul- 


\begin{tabular}{|c|c|c|}
\hline $\begin{array}{l}\text { Characteristics } \\
\text { (at enrollment) }\end{array}$ & UC (n. = 52) & $C D(n .=90)$ \\
\hline \multicolumn{3}{|l|}{ Site of disease, n. (\%) } \\
\hline & Pancolitis: 25 (48.1) & Ileocolic: 47 (52.2) \\
\hline & Left colitis: 22 (42.3) & Ileal: 25 (27.8) \\
\hline & Proctitis: 4 (7.7) & Colic: 17 (18.9) \\
\hline & Ileal colitis: 1 (1.9) & Proctitis: 1 (1.1) \\
\hline \multicolumn{3}{|l|}{ Comorbidities, n. (\%) } \\
\hline • No & $38(73.1)$ & $67(74.4)$ \\
\hline - 1 & $11(21.2)$ & $18(20.0)$ \\
\hline - 2 or more & $3(5.8)$ & $5(5.6)$ \\
\hline Comorbidities, mean \pm SD & $0.40 \pm 0.87$ & $0.37 \pm 0.79$ \\
\hline \multicolumn{3}{|c|}{ Extra-intestinal manifestations, n. (\%) } \\
\hline • No & $43(82.7)$ & $67(74.4)$ \\
\hline - 1 & $8(15.4)$ & $18(20.0)$ \\
\hline - 2 or more & $1(1.9)$ & $5(5.6)$ \\
\hline $\begin{array}{l}\text { Extra-intestinal manifestations, } \\
\text { mean } \pm \mathrm{SD}\end{array}$ & $0.21 \pm 0.54$ & $0.31 \pm 0.57$ \\
\hline $\begin{array}{l}\text { Previous treatment with } \\
\text { steroids, n. (\%) }\end{array}$ & $51(98.1)$ & $82(91.1)$ \\
\hline $\begin{array}{l}\text { Previous treatment with } \\
\text { steroids, mean duration } \\
\text { (months) } \pm \mathrm{SD}\end{array}$ & $13.7 \pm 18.5$ & $11.4 \pm 28.3$ \\
\hline Steroids at enrollment, n. (\%) & $27(51.9)$ & $76(84.4)$ \\
\hline $\begin{array}{l}\text { Previous treatment with } \\
\text { biological drugs, n. (\%) }\end{array}$ & $11(21.2)$ & $40(44.4)$ \\
\hline $\begin{array}{l}\text { Previous treatment with } \\
\text { biological drugs, mean } \\
\text { duration (months) } \pm S D\end{array}$ & $3.9( \pm 10.2)$ & $12.8( \pm 17.9)$ \\
\hline Previous surgery, n. (\%) & $0(0.0)$ & 44 (48.9) \\
\hline
\end{tabular}

Table I. Main clinical characteristics of enrolled patients $(n .=142)$ $\mathrm{CD}=$ Crohn's disease; $\mathrm{UC}=$ ulcerative colitis

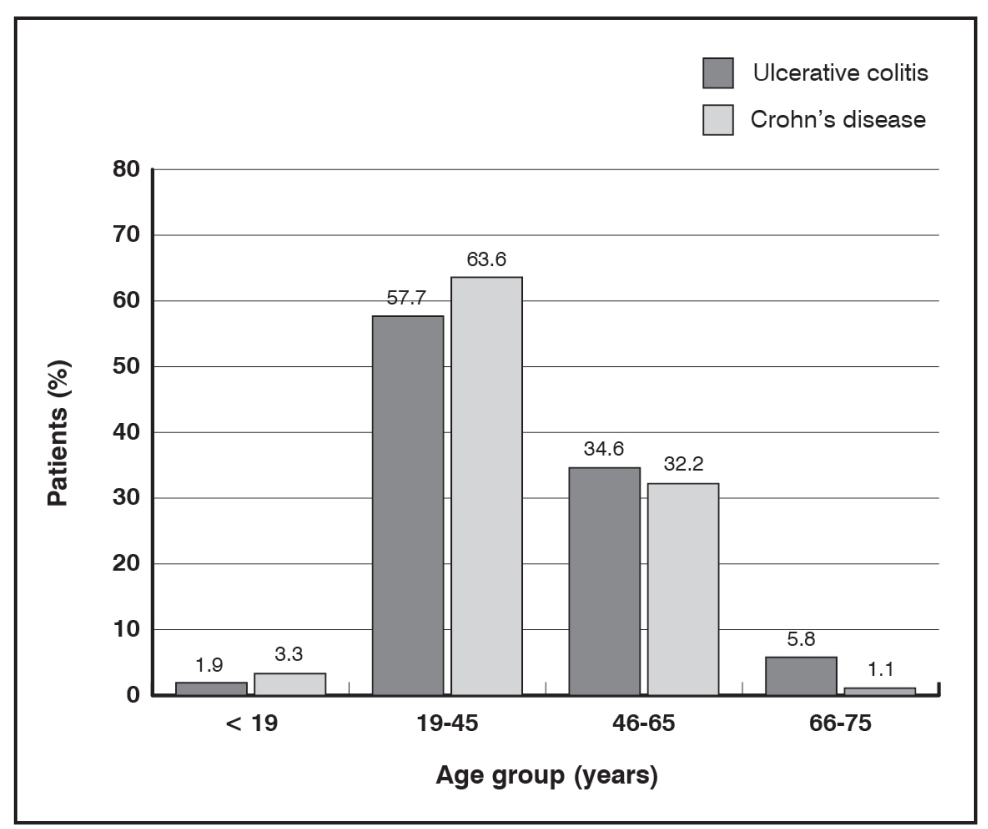

Figure 1. Stratification by age group

ly decrease in more advanced age groups (46-65 years and 66-75 years) (Figure 1). The mean age of the onset of disease was $35.7 \pm$ 13.3 years for $\mathrm{UC}$ and $29.5 \pm 14.1$ years for
$\mathrm{CD}$, while the average disease duration was $8.5 \pm 8.2$ years for $\mathrm{UC}$ and $9.2 \pm 7.7$ years for $\mathrm{CD}$.

The main clinical characteristics are summarized in Table I. The presence of one or more comorbidities was documented in $27 \%$ of the cases of UC and in $25.6 \%$ of cases of CD. In both groups the most frequent comorbidity was arterial hypertension (UC: $12.0 \%$; CD: $7.8 \%$ ). Extra-intestinal manifestations were present in $17.3 \%$ of patients with UC and in $25.6 \%$ of those with CD. Almost half of the sample of patients with CD (48.9\%) were characterized by a prior surgical history; while in the ulcerative colitis group no surgery had been carried out before enrollment. Figure 2 shows the severity of IBD upon enrollment. A picture emerges of a more compromised disease activity in patients with UC than in those with $\mathrm{CD}$.

\section{Treatments administered}

$98.1 \%$ of patients with UC and $91.1 \%$ of those with $\mathrm{CD}$ received a previous treatment with steroids (Table I). Upon enrollment, patients treated with steroids with a diagnosis of $\mathrm{UC}$ and $\mathrm{CD}$ are 27 (51.9\%) and 76 (84.4\%), respectively (Table I). Upon enrollment, $21.2 \%$ of patients with UC and $44.4 \%$ of those with $\mathrm{CD}$ were already being treated with a biologic for an average duration of 3.9 \pm 10.9 months and $12.8 \pm 17.9$, respectively. The follow-up period was $13.1 \pm 4.0$ months for patients with UC and $14.7 \pm 3.2$ months for those with CD. During this period, four patients with a diagnosis of $\mathrm{CD}(4.4 \%)$ achieved a remission. During the follow-up period, $46.2 \%$ of patients with UC changed or discontinued the biological drug received upon enrollment; this also happened in $34.4 \%$ of patients with $\mathrm{CD}$. The most frequent reason for switch/discontinuation was therapeutic failure (UC: $79.2 \%$; CD: $58.1 \%$ ).

Just under half (48.1\%) of the subjects with UC was being treated with a biologic administered subcutaneously, while in patients with $\mathrm{CD}$ this percentage was just over half (54.4\%). Both for UC and CD, the treatment with a biologic administered intravenously (infliximab) was characterized by a higher concentration of patients in the severity class compared to the biological drug administered subcutaneously (Table II). With reference to $\mathrm{UC}$ - the only setting in which the subcutaneous indication for both biological drugs was present - the subjects being treated with adalimumab showed a severity from remission to moderate, while those treated with golimumab a severity from moderate to severe (Table II). 


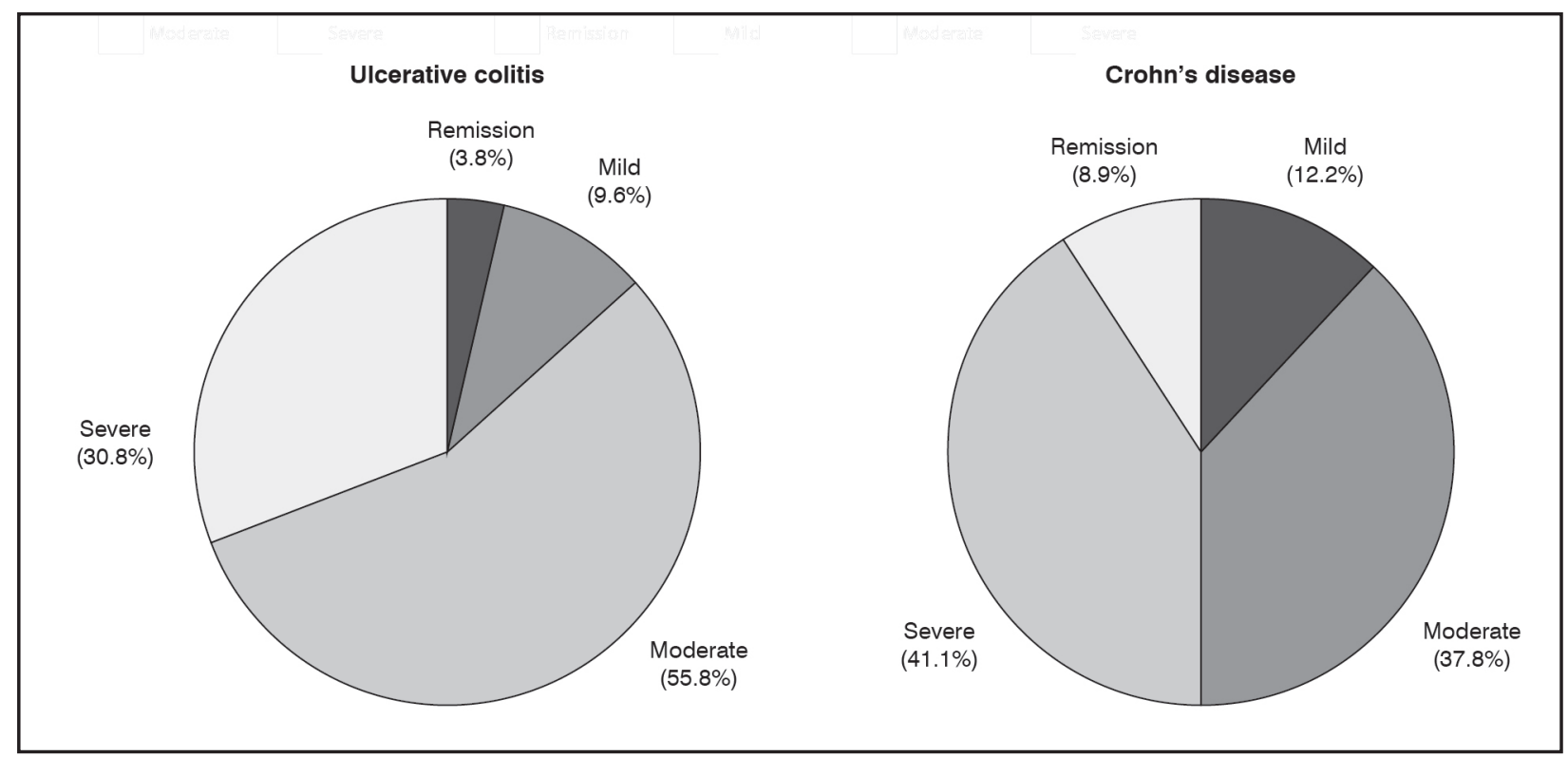

Figure 2. Severity of IBD upon enrollment

Infliximab (51.9\%) was the biological drug most commonly prescribed for patients diagnosed with UC, followed by golimumab $(26.9 \%)$ and adalimumab (21.2\%). Adalimumab was the biologic most frequently used for patients with $\mathrm{CD}(54.4 \%)$, followed by infliximab (45.6\%).

\section{Treatment Cost}

The mean cost per month of treatment amounted to $€ 1,235.41 \pm 358.38$ for patients with UC and to $€ 1,148.92 \pm 337.36$ for those with CD (Table III). In both cases, the cost item associated with the consumption of biological drugs covers over $80 \%$ of the mean overall cost. The difference in the mean cost between the two IBDs ( $€ 86.49)$ was not statistically significant $(\mathrm{p}=0.16)$.

For both UC (males: $€ 1,334.14 \pm 327.30$; females: $€ 1,168.53 \pm 368.08)$ and for $C D$ (males: $€ 1,207.59 \pm 341.14$; females: $€$ $1,072.19 \pm 325.64)$ the mean monthly treatment cost calculated for males was higher than that for females; the differences are not significant (UC: $€ 165.61 \mathrm{p}=0.10 ; \mathrm{CD}: €$ $135.41 \mathrm{p}=0.06)$.

Crossing the variables "age group" and "treatment cost" did not show any correlation. On the contrary, Figure 3 shows a significant ( $p$ $<0.01)$ correlation for both UC and for CD between the mean cost per month of treatment and the severity class: the increasing of the latter increases the cost of treatment. The presence of comorbidities upon enrollment determines a slight and non-significant increase in the cost of treatment for both UC (presence of comorbidities: $€ 1,275.05 \pm$ 181.03; absence of comorbidities: $€ 1,220.81$ $\pm 405.18 ; \mathrm{p}=0.52$ ) and CD (presence of co-

\begin{tabular}{lcccc}
\hline & \multicolumn{4}{c}{ Severity (\% pts) } \\
\cline { 2 - 5 } & Remission & Mild & Moderate & Severe \\
\hline UC & & & & \\
• IV & 0.0 & 11.1 & 51.9 & 37.0 \\
• SC & 8.0 & 8.0 & 60.0 & 24.0 \\
- Adalimumab & 18.2 & 18.2 & 63.6 & 0.0 \\
• Golimumab & 0.0 & 0.0 & 57.1 & 42.9 \\
CD & & & & \\
- IV & 4.9 & 31.7 & 48.8 & 14.6 \\
• SC & 18.4 & 42.9 & 34.7 & 4.1 \\
\hline
\end{tabular}

Table II. Patients distribution by severity and route of administration

$\mathrm{CD}=$ Crohn's disease; IV = intravenous; $\mathrm{SC}=$ subcutaneous; $\mathrm{UC}=$ ulcerative colitis

\begin{tabular}{lcc}
\hline \multicolumn{1}{c}{ Cost item } & UC & CD \\
\hline Biological drugs & $1,019.82$ & $1,002.81$ \\
Hospitalization & 215.59 & 146.11 \\
Total & $\mathbf{1 , 2 3 5 . 4 1}$ & $\mathbf{1 , 1 4 8 . 9 2}$ \\
\hline
\end{tabular}

Table III. Mean monthly treatment cost

$\mathrm{CD}=$ Crohn's disease; $\mathrm{UC}=$ ulcerative colitis

morbidities: $€ 1,174.64 \pm 385.23$; absence of comorbidities: $€ 1,140.09 \pm 321.38$; p $=0.71$ ). Figures 4 and 5 show, for UC and $\mathrm{CD}$, respectively, the mean cost per month of treatment divided by the number of lines of treatment administered during follow-up. In patients with UC or with CD a correlation ( $p$ $<0.01$ ) emerges between the increase in costs and the growing number of biological drugs administered.

Stratification by route of administration (IV vs SC) of the mean cost per month of treatment showed no significant differences in UC 


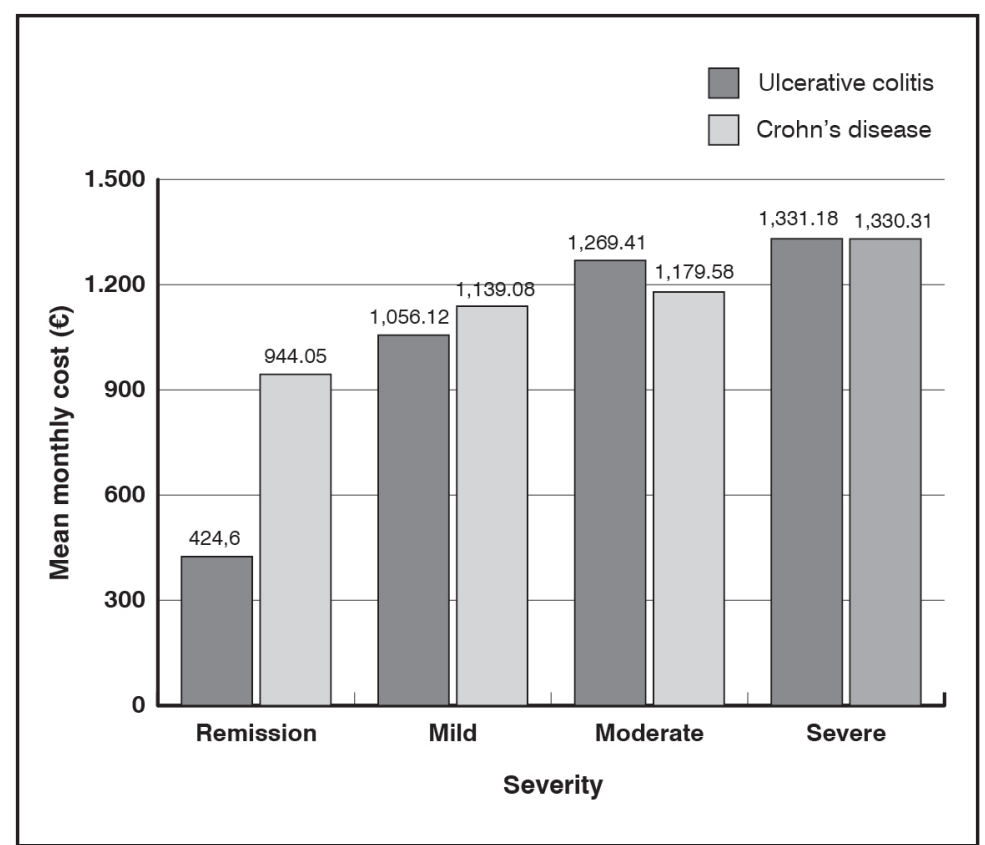

Figure 3. Correlation between the mean monthly cost and severity of disease

$(\mathrm{p}=0.99)$ or $\mathrm{CD}$ patients $(\mathrm{p}=0.98)($ Table IV). Finally, Table V presents the results of the only possible comparison between homogeneous treatment groups, divided according to the active principle administered upon enrollment. Since infliximab is the only active principle administered intravenously and golimumab is not indicated in the treatment of $\mathrm{CD}$, the analysis is limited to the comparison between adalimumab and golimumab in the treatment of UC. In this specific case, the comparison was made considering the "moderate" severity class only, since it was the only one characterized by the presence of patients treated with adalimumab or golimumab (Table II). Excluding the subjects with a prior surgical or biological history, the comparison was made considering 7 patients treated with adalimumab and 6 with golimumab (Table V). The difference in the mean cost per month of treatment (€ 69.18) between adalimumab and golimumab was not statistically significant ( $\mathrm{p}$ $=0.45$ ). The higher mean cost of the biological drug associated with adalimumab is offset by the lower number of hospitalizations. This increased number of hospitalizations of the patients who start treatment with golimumab may be a consequence of the longer disease duration (10.1 years vs 4.1 years, $\mathrm{p}=0.21$ ).

\section{DISCUSSION}

This retrospective, observational study was conducted with the aim to estimate the cost of the disease associated with patients with a diagnosis of UC or CD in Italy. The sample base, consisting of 142 patients (mean age $40.8 \pm 14.0$ years), was constructed enrolling all patients who, with a diagnosis of UC or $\mathrm{CD}$ and in treatment with biologics, were referred to the Center during the period May 2015-April 2016.

The mean cost per month of treatment was consistent for the two diseases (UC: $€$ $1,235.41 \pm 358.38$; CD: $€ 1,148.92 \pm 337.36$; $\mathrm{p}=0.16)$. In both groups, the main cost item is represented by biologics (more than $80 \%$ of the total). Overall, that is both for UC and for $\mathrm{CD}$, the mean cost per month of treatment increases with the severity of the disease. It is also notable how the cost item associated with hospitalizations grows with the increase in severity, going - as expressed as an incidence on the total cost - from $0 \%$ for the remission to $26-30 \%$ for the severe status. The mean cost per month of treatment also grows with the increase in the number of treatment lines $(\mathrm{p}<0.01)$.

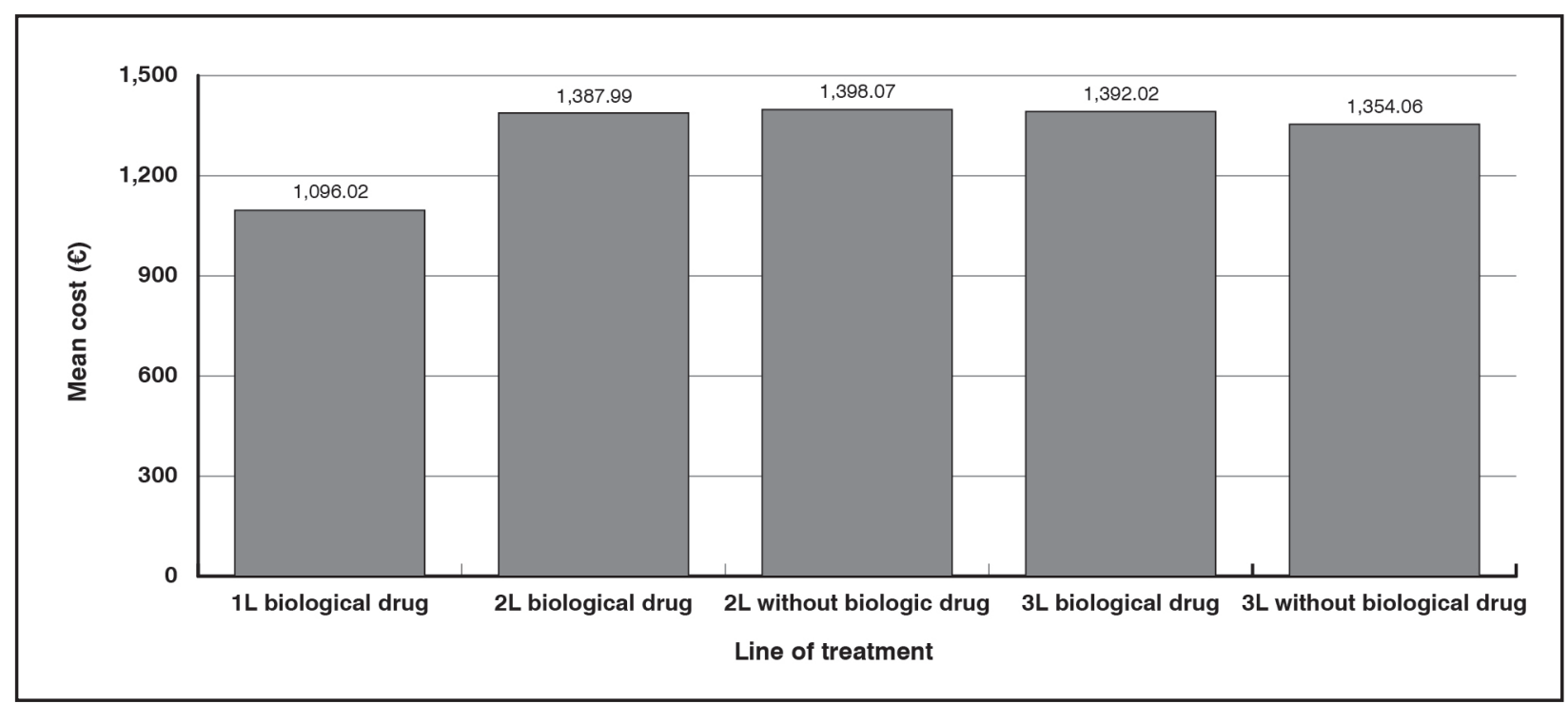

Figure 4. Mean cost per line of treatment (ulcerative colitis) 


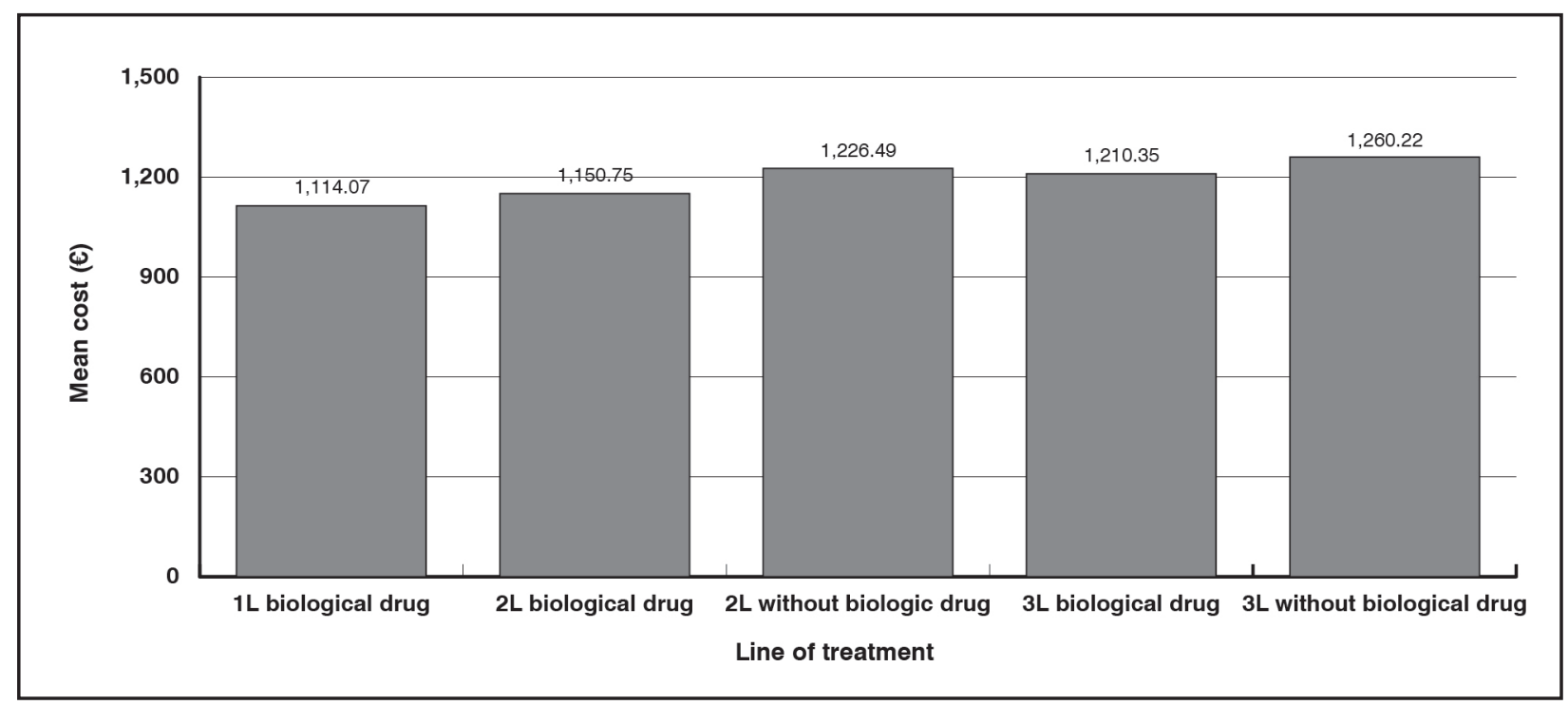

Figure 5. Mean cost per line of treatment (Crohn's disease)

Further analyses conducted between cost, route of administration and active ingredients did not show any appreciable difference. Although the comparison of the mean cost associated with biological drugs administered subcutaneously, compared to intravenously, did not show any significant differences, it should be noted that the biologics given intravenously, however, require a greater investment in terms of time by both the healthcare professional and the patient.

The distribution of patients by severity would seem to bring out some differences in the choice of the biological therapy administered. Intravenous biological therapy would appear to be administered to more compromised patients; while between the two biological drugs administered subcutaneously in UC, golimum$\mathrm{ab}$ would seem to be used more frequently in subjects with a longer and more severe history of disease than those treated with adalimumab. Finally, with regard to the average purchase prices of the biologics considered here, it should be noted that for adalimumab and golimumab the current sales price decreased by $5.0 \%$ and $3.1 \%$, respectively. The application of these discounts, however, would not significantly modify the results proposed here.

Among the limitations attributable to this analysis, some should be highlighted. First, the sample refers to a single Center. Unfortunately, there are no elements to establish to which extent it could be considered representative of the entire Italian reality, or how over- or under-estimated, with respect to the latter, could be the costs of the disease reported in this study. The availability of a few other center would have made it possible to ascertain the degree of information disparity existing between each of them.

\begin{tabular}{lcc|cc}
\hline & \multicolumn{2}{c|}{ UC } & \multicolumn{2}{c}{ CD } \\
\cline { 2 - 5 } & IV & SC & IV & SC \\
\hline Patients, n. & 27 & 25 & 41 & 49 \\
Mean age, years & 43,4 & 45,2 & 42,9 & 35,3 \\
$\begin{array}{l}\text { Mean disease duration, } \\
\text { years }\end{array}$ & 9,8 & 7,1 & 9,4 & 9,1 \\
$\begin{array}{l}\text { Mean follow-up, months } \\
\text { Mean monthly cost, }\end{array}$ & 13,0 & 13,1 & 14,5 & 14,9 \\
$€($ SD) & $1,234.99$ & $1,235.87$ & $1,149.93$ & $1,148.07$ \\
\hline
\end{tabular}

Table IV. Mean cost per month of treatment: subcutaneous (SC) vs intravenous (IV) administration

$\mathrm{CD}=$ Crohn's disease; IV = intravenous; $\mathrm{SC}$ = subcutaneous; $\mathrm{SD}$ = standard deviation; $\mathrm{UC}=$ ulcerative colitis

\begin{tabular}{lcc} 
& \multicolumn{2}{c}{ Biologic at enrollment } \\
\cline { 2 - 3 } & Adalimumab & Golimumab \\
\hline Diagnosis & UC & CD \\
Patients, $n$. & 7 & 6 \\
Age, years & 42.6 & 48.7 \\
Disease duration, years & 4.1 & 10.0 \\
Previous treatment with biologic & No & No \\
Previous surgery & No & No \\
Severity of disease & Moderate & Moderate \\
Follow-up, months & 11.1 & 10.3 \\
Biologic cost, $€ /$ month & $1,310.08$ & $1,285.62$ \\
Hospitalization cost, $€ /$ month & 0.00 & 93.65 \\
Total cost, $€ /$ month (SD) & $1,310.08(125.50)$ & $1,379.26(161.73)$ \\
\hline
\end{tabular}

Table V. Mean cost per month of treatment: adalimumab vs golimumab $\mathrm{CD}=$ Crohn's disease $\mathrm{SD}=$ standard deviation; $\mathrm{UC}=$ ulcerative colitis

Second, the enrollment sample was not dimensioned in order to have a certain precision in the estimation of the average cost in the two main groups (UC and CD), although 
the variability of the costs appeared to be contained. Therefore, the dimension of the subgroups were also limited. Probably also for this reason some of the differences found in the analysis were found to be significant. It should however be clarified that the study had no objectives in this sense, nor the sample was dimensioned in terms of statistical power.

Third, the cost analysis collected information only on the costs determined by biological therapy and hospitalizations; other cost items were not considered (eg. specialist visits, etc.), which however are potentially interesting for those wishing to examine in detail the knowledge of the resources required by UC or CD. In this respect, it is to be emphasized that the choice of a therapy administered subcutaneously or intravenously may result in a different economic impact borne both by the hospital - expressed in terms of time dedicated by doctors and nurses - and the patient (and/or caregiver) - expressed in terms of reduced work performance (number of working days lost due to the disease).

The treatment of IBD represents a significant burden from all perspectives, especially when considering the NHS's and the society's in its entirety. A recent European study (ECCO-EpiCom Study) estimated the cost of treating patients with IBD in the first year of diagnosis [22].The study enrolled 1,367 patients referred to 31 Hospital Centers located in Western (WE) and Eastern Europe (EE), 710 of whom diagnosed with UC, 509 with $\mathrm{CD}$ and 148 with unspecified IBD. The total expenditure associated with the entire cohort was $€ 5,408,174$ (diagnostics: $€ 2,042,990$ [38\%], surgery: $€ 1,427,648$ [26\%], biologics: $€ 781,089$ [14\%] and standard therapy: $€$ $1,156,520[22 \%])$, with an average cost of $€$ $3,956.23$ (recalculated on a monthly basis as equal to $€ 369.69$ ). The significant difference in the cost of treatment that emerges compared to what was found here is mainly due to the heterogeneity of the two cohorts considered. In this analysis only patients receiving biologics with a history of disease established over time (about 9 years on average) were considered. On the contrary, patients enrolled in the European study are in the first year of treatment, and therefore make a lesser use of the biological therapy (average cost recalculated on a monthly basis: $€ 47.16$ ) and of surgery (average annual cost per patient: $€ 87.03$ ).

The results estimated here, with the necessary limitations, would seem to be in line with those estimated by a recent analysis conducted in the United States [23]. The American analysis compared the direct medical costs associated with 539 patients with $\mathrm{CD}$ to a control group without any diagnosis of IBD. The average annual cost per patient with CD amounted to US \$13,446, against the US \$ 6,029 associated with subjects without IBD. If recalculated on a monthly basis (US $\$ 1,120.5$ ), the average cost estimated by the American study comes to have an order of magnitude similar to that estimated here (CD: $€ 1,148.92)$.

Finally, it is also interesting the comparison with the average costs by severity calculated from a recent analysis conducted in Australia on 175 patients with UC [24]. The average direct healthcare cost calculated over a time horizon of three months of treatment was AU $\$ 2,914$. The analysis conducted by severity reported costs rising with the increase in severity (remission: AU \$ 1,970; mild activity: AU \$ 3,736 and moderate/severe activity: AU \$ 4,162). These data confirm what was found here: the importance of severity as a cost driver.

\section{CONCLUSIONS}

The data collected and presented here, albeit limited to a single experience referred to a Center in Northeast Italy, would seem sufficient to state that both UC and CD are pathologies characterized by an overall rather high cost borne by the National Health Service, and that, due to chronicity, this cost is likely to increase with the progression of the severity of the conditions.

From the treatment cost data, a further indication would finally seems to emerge, to be kept in mind during the biological treatment selection process. Since the various comparisons carried out (SC therapy vs IV therapy; adalimumab vs golimumab) showed no significant differences between the costs of treatment, it is believed that the choice of the biological drug should be made taking into greater account the clinical aspects, and that therefore the cost of treatment would not be the only choice driver.

\section{Funding}

No financial support was received for this submission.

\section{Conflict of interest}

The authors have no conflict of interest to declare. 


\section{REFERENCES}

1. Schneider Y, Saumoy M, Cohen-Mekelburg S, et al. The Cost-Effectiveness of Vedolizumab for Inflammatory Bowel Disease: A Review of the Current Literature. Gastroenterol Hepatol (NY) 2016; 12: 617-21

2. AMICI Onlus. Associazione Nazionale per le malattie infiammatorie corniche dell'intestino. Available at https:// amiciitalia.eu/ (last accessed March 2017)

3. Burisch J, Munkholm P. The epidemiology of inflammatory bowel disease. Scand J Gastroenterol 2015; 50: 94251; https://doi.org/10.3109/00365521.2015.1014407

4. Brunner-Suddarth. Nursing medical-surgical. 4th ed. Milano: CEA, 2010

5. Irvine EJ. Quality of life of patients with ulcerative colitis: past, present, and future. Inflamm Bowel Dis 2008; 14 : 554-65; https://doi.org/10.1002/ibd.20301

6. Bodger K. Cost of illness of Crohn's disease. Pharmacoeconomics 2002; 20: 639-52; https://doi.org/10.2165/00019053200220100-00001

7. Ward FM, Bodger K, Daly MJ, et al. Clinical economics review: medical management of inflammatory bowel disease. Aliment Pharmacol Ther 1999; 13: 15-25; https://doi.org/10.1046/j.1365-2036.1999.00437.x

8. Bassi A1, Dodd S, Williamson P, et al. Cost of illness of inflammatory bowel disease in the UK: a single center retrospective study. Gut 2004; 53: 1471-8; https://doi.org/10.1136/gut.2004.041616

9. Bressler B, Marshall JK, Bernstein CN, et al. Clinical practice guidelines for the medical management of ulcerative colitis nonhospitalized: the Toronto consensus. Gastroenterology 2015; 148: 1035-58. e3

10. Thomas A, Lodhia N. Advanced therapy for inflammatory bowel disease: a guide for the primary care physician. J Am Board Fam Med 2014; 27: 411-20; https://doi.org/10.3122/jabfm.2014.03.130224

11. Danese S, Vuitton L, Peyrin-Biroulet L. Biologic agents for IBD: practical insights. Nat Rev Gastroenterol Hepatol 2015; 12: 537-45; https://doi.org/10.1038/nrgastro.2015.135

12. Park KT, Bass D. Inflammatory bowel disease-attributable costs and cost-effective strategies in the United States: a review. Inflamm Bowel Dis 2011; 17: 1603-9; https://doi.org/10.1002/ibd.21488

13. Huoponen S, Blom M. A Systematic Review of the Cost-Effectiveness of Biologics for the Treatment of Inflammatory Bowel Diseases. PLoS One 2015; 10: e0145087; https://doi.org/10.1371/journal.pone.0145087

14. Choy T, Jackson J. Biologic agents in the management of inflammatory bowel disease: is it worth it? UWOMJ 2012;81:2

15. Mehta F. Economic Implications of Inflammatory Bowel Disease and Its Management. Am J Manag Care 2016; 22: S51-S60

16. Schroeder KW, Tremaine WJ, Ilstrup DM. Coated oral 5-aminosalcylic acid therapy for mildly to moderately active ulcerative colitis. N Eng J Med 1987; 317: 1625-9; https://doi.org/10.1056/NEJM198712243172603

17. Rutgeerts P, Sandborn WJ, Feagan BG, et al. Infliximab for induction and maintenance therapy for ulcerative colitis. N Engl J Med 2005; 353: 2462-76; https://doi.org/10.1056/NEJMoa050516

18. Harvey RF, Bradshaw JM. A simple index of Crohn's-disease activity. Lancet 1980; 315: 514; https://doi.org/10.1016/ S0140-6736(80)92767-1

19. British Columbia Ministry of Health Services. Worksheet based on the Harvey-Bradshaw Index. British Columbia Ministry of Health Services. Available at https://www.health.gov.bc.ca/exforms/pharmacare/5374fil.pdf (last accessed Mach 2017)

20. Sandborn WJ, Feagan BG, Hanauer SB, et al. A review of activity indices and efficacy endpoints for clinical trials of medical therapy in adults with Crohn's disease. Gastroenterology 2002; 122: 512-30; https://doi.org/10.1053/ gast.2002.31072

21. Interregional agreement to compensate the health mobility. Conference of Regions and Autonomous Provinces 13/41/CR05a/C7

22. Burisch J, Vardi H, Pedersen N, et al. Cost and resource utilization for diagnosis and treatment during the initial year in a European inflammatory bowel disease inception cohort: an ECCO-EpiCom Study. Inflamm Bowel Dis 2015; 21: 121-31; https://doi.org/10.1097/MIB.0000000000000250

23. Ganz ML, Sugarman R, Wang R, et al. The Economic and Health-related Impact of Crohn's Disease in the United States: Evidence from a Nationally Representative Survey. Inflamm Bowel Dis 2016; 22: 1032-41; https://doi. org/10.1097/MIB.0000000000000742

24. Gibson PR, Vaizey C, Black CM, et al. Relationship between disease severity and quality of life and assessment of health care utilization and cost for ulcerative colitis in Australia: a cross-sectional, observational study. J Crohn's Colitis 2014; 8: 598-606; https://doi.org/10.1016/j.crohns.2013.11.017 